\title{
Oxygen Penalty for Waste Oxidation in an Advanced Life Support System - A Systems Approach
}

\author{
Suresh Pisharody and K. Wignarajah \\ Lockheed Martin Space Mission Systems \& Services \\ John Fisher \\ NASA Ames Research Center
}

Copyright (C) 2002 Society of Automotive Engineers, inc.

\begin{abstract}
Oxidation is one of a number of technologies that are being considered for waste management and resource recovery from waste materials generated on board space missions. Oxidation processes are a very effective and efficient means of clean and complete conversion of waste materials to sterile products. However, because oxidation uses oxygen there is an "oxygen penalty" associated either with resupply of oxygen or with recycling oxygen from some other source. This paper is a systems approach to the issue of oxygen penalty in life support systems and presents findings on the oxygen penalty associated with an integrated oxidation-SabatierOxygen Generation System (OGS) for waste management in an Advanced Life Support System. The findings reveal that such an integrated system can be operated to form a variety of useful products without a significant oxygen penalty.
\end{abstract}

\section{INTRODUCTION}

Solid waste management is important for any human mission, whether it is a near term mission such as the ISS or a long duration mission such as an exploration mission to Mars or the moon. Appropriate methods to manage wastes are important to meet the constraints of space and resources to provide for crew safety. Waste management systems will vary depending on the duration of the mission. A short duration or involving regular re-supply would be different from a long-term mission, where self-sufficiency is desirable because of resupply constraints. A wide array of potential technologies exists and the development of technologies will depend on their efficiencies, crosscutting nature, products, safety, operational reliability and other factors. The choice of technologies to develop will depend on the return on research dollar and on the capability to reduce mission cost. At the same time all the constraints and requirements of the mission and waste processing must be met. To this end, the advanced life support community has been involved in developing a criteria list and identifying mission requirements to focus on development of technologies that are the most promising (Levri, et al., 2001).

Oxidation has been the subject of study for waste management for several years as the most promising technology because it completely oxidizes waste material to benign products such as carbon dioxide, water and inorganic ash. Thus it reduces storage space required, removes the biohazards associated with storage of biohazardous material, recovers water, and recovers inorganic plant growth nutrients. On the other hand, oxidation also requires oxygen, an important resource on any mission. Previous studies (Lee, 2001; Maxwell and Drysdale 2001) have imposed a significant oxygen penalty on the use of oxidation technologies for waste management. This reduces its competitiveness as a promising technology compared to other waste management technologies that do not need oxygen. This study examines the oxygen penalty associated with an oxidation system when it is considered as part of the overall advanced life support system.

\section{PRIOR SYSTEMS ANALYSIS}

Systems analysis work on waste processing in the last few years has resulted in reports or papers by Gertner (Gertner, 1999), Lee (Lee, 2001), and Maxwell (Maxwell and Drysdale, 2001). The Gertner report evaluated competing oxidative technologies, Supercritical Water oxidation (SCWO) and incineration and concluded that Incineration and SCWO are equally effective and efficient for long term human space missions, on an ESM (Equivalent System Mass) basis. The Lee report was a detailed systems analysis of several waste treatment technologies for sterilization and water recovery. This report, which focused on sterilization and water recovery on intermediate term missions such as Mars Transit, 
showed that incineration had the lowest ESM followed by autoclaving-lyophilization. However, the report also showed a large oxygen resupply requirement for incineration that could make it very unattractive. The autoclave-lyophilization system has the lowest ESM if the oxygen must be supplied without recycle for the incineration process.

The approach of the Lee analysis was to treat all the waste without segregation. Lee considered a total waste stream that contains polyethylene plastic packages, tapes and filters, which formed $83 \%$ of the total dry weight of the wastes processed. Polyethene packages, tapes, and filer contain roughly only $20 \%$ by weight of water to be recovered and do not contain much oxygen that can be utilized in its oxidation.

The Lee analysis did not look in detail for ways to reduce the oxygen penalty. The ways to reduce the oxygen penalty include segregating portions of the waste for separate treatment and/or integrating the oxidation processor with other life support processors to recover oxygen. Feces, for instance, is very appropriate for oxidation because it contains a large amount of oxygen and water, and because feces is already separated from other wastes. Integration with other life support processors means taking advantage of processors that clearly will already be present in advanced support systems such as Sabatier and OGS, or adding other processors such as the carbon formation reactor (CFR). A CFR can take the methane produced by a Sabatier and convert it to carbon. When oxygen and hydrogen are both scarce in a life support system, a CFR conserves these elements by keeping them from being bound to waste carbon. The ways to reduce the oxygen penalty involve sending the right waste to the right processor and using processors that integrate in a manner that leaves the ultimate waste (carbon, carbon dioxide, methane, etc.) in a form that best conserves system resources.

The Maxwell analysis was a comparison of a number of waste technologies based on ESM. The oxidation technologies in this analysis were burdened with oxidation penalties that were not optimized by the method discussed in this paper. As such, the relative ESM of oxidation technologies such as incineration and supercritical water oxidation will fare much better when compared with other technologies when methods of oxygen penalty reduction and water reclamation are included.

\section{APPROACH}

The systems analysis approach in this study was based on several factors that were incompletely considered or missing in previous reports.

1. Oxidation recovers water. It is especially good at water recovery when it is integrated with Sabatier and OGS. Water is an important resource to be recovered for any long duration human mission scenario. Water recovery is of limited value only when a mission is "water rich." "Water rich" means that the mission has so much water available that reclamation of water is unnecessary. There are numerous ways that water is gained and lost on a mission, and it is the overall balance of sources and sinks that determines whether a mission is water rich. Calculation of the balance of the sources and sinks for water is uncertain, and flexibility in the system would appear to be very valuable. In addition, the cost of bringing along a large enough store of water to make the whole mission water rich would be very high.

With transportation costs for a round trip to Mars approaching $\$ 2,000,000$ per $\mathrm{kg}$ of payload (based on the commonly used $\$ 20,000$ per $\mathrm{kg}$ to low Earth orbit and the multiplying propulsion factor for a round trip to and from Mars of about $100 \mathrm{~kg}$ of propulsion per $\mathrm{kg}$ of payload (Larsen, et al.)), it is hard to imagine systems that will be water rich. Unnecessary water will be eliminated from the initial payload mass whenever possible to reduce costs. Even if the cost of extra water is deemed psychologically necessary, in hydrated food for instance, only portions of a mission are likely to be water rich (parts of missions with significant EVA will not be water rich). Additionally, the water would be contained in stored food. Water in stored food is not available to meet the demands for water during contingencies or when there is an immediate demand for significant amounts of water. Recovery of water during a mission means that less water supply is necessary initially, and this significantly reduces mission cost.

2. Oxidation makes very good sense for feces because oxidation renders a noxious waste nonbiohazardous and chemically inert, because feces contains significant amounts of oxygen that aid oxidation, and because water can be recovered from feces by oxidation.

3. Plastic packaging may not need oxidation processing because it contains limited resources such as oxygen or water to be recovered and because plastic is not nearly as biohazardous as feces. A CFR can be used to keep the ESM low for oxidation of plastics. A CFR is useful because the low oxygen and water in the plastics probably requires conversion of at least some of the carbon in the plastic to pure carbon (via CFR) in order to avoid loss of valuable water or oxygen. Use of a CFR is not discussed in detail in this paper because its use adds some complexity to the description of the integrated 
system without changing the fundamental point that oxidation can be conducted without a large penalty.

4. Advanced life support systems make use of the Sabatier process and the oxygen generation system to recover oxygen from carbon dioxide. In this paper an integrated oxidation-SabatierOGS system is considered for waste management analysis. The oxygen penalty associated with such an integrated system is considered for an intermediate term mission such as a Mars transit mission. The "oxygen penalty" is the increase in size and power of the Sabatier and OGS system to handle the gas streams from the solid waste processing system.

5. The components of waste can be segregated at the collection point. Consequently, two different waste streams are considered for comparison. The two waste streams considered are: 1) Wet feces only. 2) Feces and the other wet wastes generated in an advanced life support system for an intermediate mission such as Mars transit, for a six person crew, with the exception of plastic packaging and tapes.

Crew time is not included in this analysis. The systems discussed can be automated to the point that crew time is negligible. Other assumptions included in this analysis: trace contaminant control is included in the oxidation ESM, no credit is assumed for reuse of combustion heat, cooling and condensation of the not combustion gas is included.

A spreadsheet model was created for the integrated oxidation-sabatier-OGS system. The system was modeled to maximize water and oxygen recovery and minimized for carbon dioxide formation. The feed values and component values, water content, crew-size, batch size can be readily changed to evaluate the effect of these variables on the integrated system. The model can also evaluate the effect of a carbon formation reactor. ESM values for the Sabatier, OGS system and the ESM conversion factors were taken from the BVAD document (Drysdale and Hanford, 1999). ESM values based on mass, power, cooling, and volume for the oxidation system and the lyophilizer were taken from the Lee report.

Figure 1 shows a simplified conceptual version of the system design. The system considers an oxidation system in conjunction with a Sabatier and an oxygen generation system (OGS). Sabatier and OGS are assumed to be a part of an Advanced Life Support System (BVAD, 1999). The diagram implies that by appropriate sizing of the internal flow streams, that the input stream can be converted to any combination of the output streams so long as an elemental balance can be made. Note that if a Carbon Formation Reactor (CFR) were to be included in this system, then $C$ (carbon) could be included in the exit materials, further enhancing the flexibility of the system. The relevant reactions are below. The formula for the waste below was developed from the ratio of the components for combined feces and wet wastes without plastic. It was normalized with respect to the carbon in the waste. See table 1 (Appendix) for more details on the breakdown of the waste.

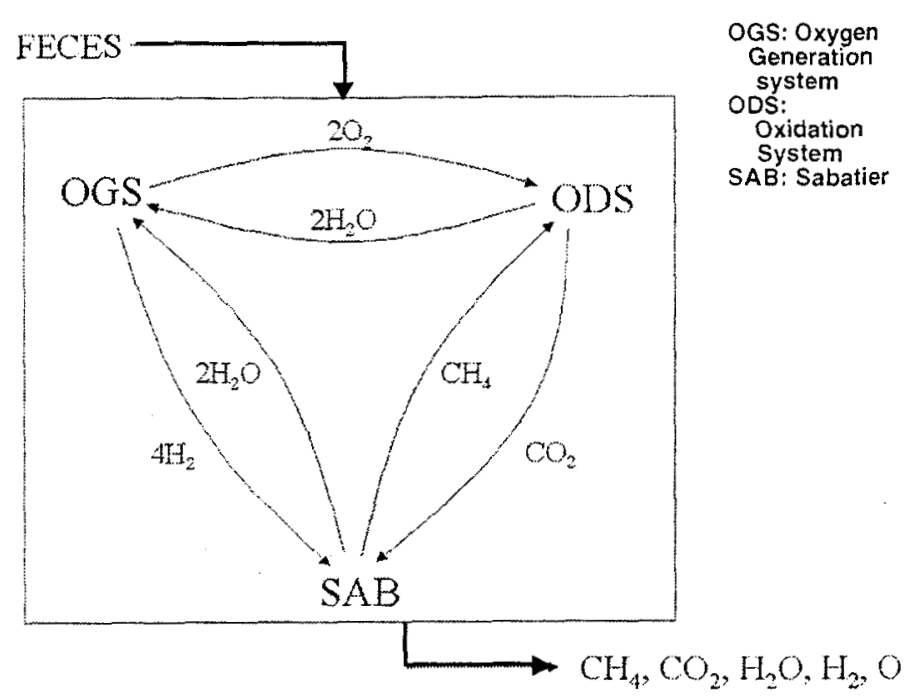

Figure 1, Simplified schematic of the oxidation-Sabatier-OGS system

\section{Oxidation:}

$\mathrm{C}_{1} \mathrm{H}_{20.2} \mathrm{O}_{10.1} \mathrm{~N}_{0.17}+\mathrm{O}_{2}=\mathrm{CO}_{2}+10.1 \mathrm{H}_{2} \mathrm{O}+0.085 \mathrm{~N}_{2}$

Sabatier: $\mathrm{CO}_{2}+4 \mathrm{H}_{2}=\mathrm{CH}_{4}+2 \mathrm{H}_{2} \mathrm{O}$

OGS: $2 \mathrm{H}_{2} \mathrm{O}=2 \mathrm{H}_{2}+\mathrm{O}_{2}$

The three formulas and the associated processors can be combined to produce a number of different overall results. These two examples illustrate this flexibility:

Overall balance to produce maximum methane without oxygen resupply:

$\mathrm{C}_{1} \mathrm{H}_{20.2} \mathrm{O}_{10.1} \mathrm{~N}_{0.17}=\mathrm{CH}_{4}+8.1 \mathrm{H}_{2} \mathrm{O}+\mathrm{O}_{2}+0.085 \mathrm{~N}_{2}$

Overall balance to produce maximum carbon dioxide without oxygen resupply:

$\mathrm{C}_{1} \mathrm{H}_{20.2} \mathrm{O}_{10.1} \mathrm{~N}_{0.17}=\mathrm{CO}_{2}+8.1 \mathrm{H}_{2} \mathrm{O}+2 \mathrm{H}_{2}+0.085 \mathrm{~N}_{2}$

Figure 1 above focuses on the integration with the oxidation system. However, the OGS and the Sabatier in an overall life support system take in water and carbon dioxide from other sources, and the streams from the other sources are much larger than the streams required to handle feces oxidation. In other words, the integration 
of the oxidation system with the Sabatier and OGS only increases the sizes of the Sabatier and OGS a small amount - approximately $10 \%$.

The input quantities of the various wastes were obtained from the Lee report and are shown in table 1 (Appendix). As can be seen from tables 3 and 4 (Appendix) all the carbon in the waste is turned into $\mathrm{CH}_{4}$. The oxygen in the waste is either converted to water or released as oxygen. In addition, the water in the waste is recovered as water. For dry wastes such as plastic, the system can be run with a carbon formation reactor added to fully reduce the carbon in the waste to form solid carbon.

The flow diagram used to model the integrated oxidationSabatier-OGS system is as shown in figure 2 (Appendix). input and output quantities are listed in the tables 3 and 4 (Appendix). The amount of the various outputs such as $\mathrm{O}_{2}$, water, $\mathrm{CH}_{4}$, and $\mathrm{CO}_{2}$ are a function of the input $\mathrm{C}$, $\mathrm{H}$, and $\mathrm{O}$; the spreadsheet was modeled to study the effects of differing input ratios to the output quantities. Internal streams (shown in the flow diagram of figure 2 (Appendix)) were calculated by unit operations mass balance (a unit operation is the Sabatier for instance). The ESM values (based on mass, power, cooling, and volume) for the oxidizer, Sabatier, oxygen generation system, and the autoclave-lyophilizer were based on the detailed analysis from the Lee report and the assumptions in the BVAD document and were scaled linearly from those documents for the present analysis.

\section{RESULTS AND DISCUSSION}

The ESM values calculated from the spreadsheet model indicate that the oxidation-Sabatier-Oxidation system does not incur a large oxygen penalty as previously estimated (Lee, 2001, Maxwell and Drysdale, 2001). The integrated system is capable of converting all the carbon in the waste to form $\mathrm{CH}_{4}$ and recovering the valuable resources such as water and oxygen. For example, no resupply is needed for the wet wastes with moisture content over $4.5 \%$. Furthermore, the integrated system is very flexible. The operation of the system can be manipulated to vary the products - trading carbon dioxide for methane was illustrated above. The analysis and results for the wet mixed wastes and feces are as shown in tables 5 and 6 (Appendix). For both cases, the primary output streams are water and oxygen. The extra water generated over 600 days for a Mars transit mission in comparison with the next best process i.e. autoclave/lyophilization is $52.87 \mathrm{kgs}$ for the wet feces case and $465.71 \mathrm{kgs}$ for the total wet waste case. If water is considered a valuable resource this results in a negative ESM. The amount of water recovered during the course of the mission more than makes up for the extra mass, power, and volume required for the incinerator, Sabatier, and OGS.

All of this water should be very valuable because, as previously mentioned, with mass worth $\$ 2,000,000$ per $\mathrm{kg}$ on a Mars mission, there is little reason to think that extra water would be taken on a such a mission (i.e. that a mission would be "water rich"). However, even in the case of a water rich portion of a mission, this processor would be a valuable asset that would provide resiliency and make-up for periodic water shortages, which in the absence of such a processor might be trapped in stored food. The rationale for choosing the oxidation-SabatierOGS system is further strengthened if the whole mission is considered, including portions when there would be extra demand for water such as during the surface stay of the mission, where there would be regular EVA activities.

The plastic packaging waste has an insignificant amount of recoverable resources, and a simple stabilization procedure may be a more appropriate way of managing the plastic wastes generated.

In this report, lyophilization-autoclaving is considered with and without venting to space. Venting means releasing contaminant volatiles formed during autoclaving to space. The ESM for contaminant cleanup increases the autoclave ESM if contaminant venting is not allowed. The oxidation system always includes contaminant cleanup and does not incur additional ESM for no venting cases. Without venting the ESM values for lyophilization/autoclaving increases by $37.3 \mathrm{~kg}$ for the feces only case and by $280 \mathrm{~kg}$ when the entire wet wastes are considered.

\section{CONCLUSIONS}

An oxidation system such as an incinerator does not incur a large oxygen penalty as previously estimated when operated in conjunction with other subsystems such as the Sabatier and the oxygen generation system. The integrated system can be applied to near term as well as long term manned missions. The oxidationSabatier-OGS system had the lowest ESM for water recovery when compared to the other waste management systems for intermediate missions such as a Mars transit mission. The oxygen penalty estimated in the previous analysis reports was unnecessarily increased by the inclusion of significant amounts of supplied oxygen to oxidize plastic packaging, a waste with no resources to be recovered.

The integrated system is very flexible and has many advantages over competing systems. The amount of individual outputs such as $\mathrm{CH}_{4}, \mathrm{H}_{2} \mathrm{O}$ and $\mathrm{O}_{2}$ can be readily varied according to needs. Oxidation systems have the added advantage of rendering the output sterile, in contrast to processes such as lyophilization, for which the products still possess the threat of contamination.

\section{REFERENCES:}

1. Carden, J.L. and Browner, R., "Preparation and Analysis of Standardized Waste Samples for Controlled Ecological Life Support Systems. NASA 
CR No. 166392, NASA Ames Research Center, Moffett Field, CA, 1982.

2. Drysdale, A.E., Hanford, A.J., "Advanced Life Support Systems Modeling and Analysis ProjectBaseline Values and Assumptions Document," (BVAD). Document Number: CTSD-ADV-371, JSC 39317, June 18, 1999.

3. Gertner, Bruce, "Comparison of Solid waste processing systems (SPS): Incineration vs. Supercritical water oxidation (SCWO) - Generalized findings of the SPS trade study," JSC report, 1999.

4. Larson, W.J., Pranke, L.K., Human Spaceflight Mission Analysis and Design, The McGraw Companies, Inc, ISBN0-07-236811-X.

5. Lee, Wen-Ching, personal communication, JSC, 2001.

6. Lee, Wen-Ching, "Solid waste processing study for initial Mars missions - Final trade study results for group two technologies," JSC report, June 27, 2001.

7. Levri, J.A., Hogan, J.A. and Alazraki, M.P., "Evaluation Criteria for Solid Waste Management Research and Technology Development, American Society for Gravitational \& Space Biology (ASGSB) $17^{\text {th }}$ Annual Meeting, Alexandria, VA Nov 7-11, 2001.

8. Maxwell, Sabrina, Alan E. Drysdale, "Assessment of Waste Processing Technologies for 3 missions," ICES, Orlando, Florida, 2001.

\section{ACKNOWLEDGEMENTS}

The authors would like to thank the Advanced Life Support Program for funding this anaiysis and our colleagues Julie Levri, Richard Lamparter and Harry Jones for their comments and suggestions.

\section{DEFINITIONS, ACRONYMS, ABBREVIATIONS}

ARC: Ames Research Center BVAD: Baseline Values and Assumptions Document CFR: Carbon Formation Reactor ESM: Equivalent System Mass JSC: Johnson Space Center OGS: Oxygen Generation System

\section{APPENDIX}

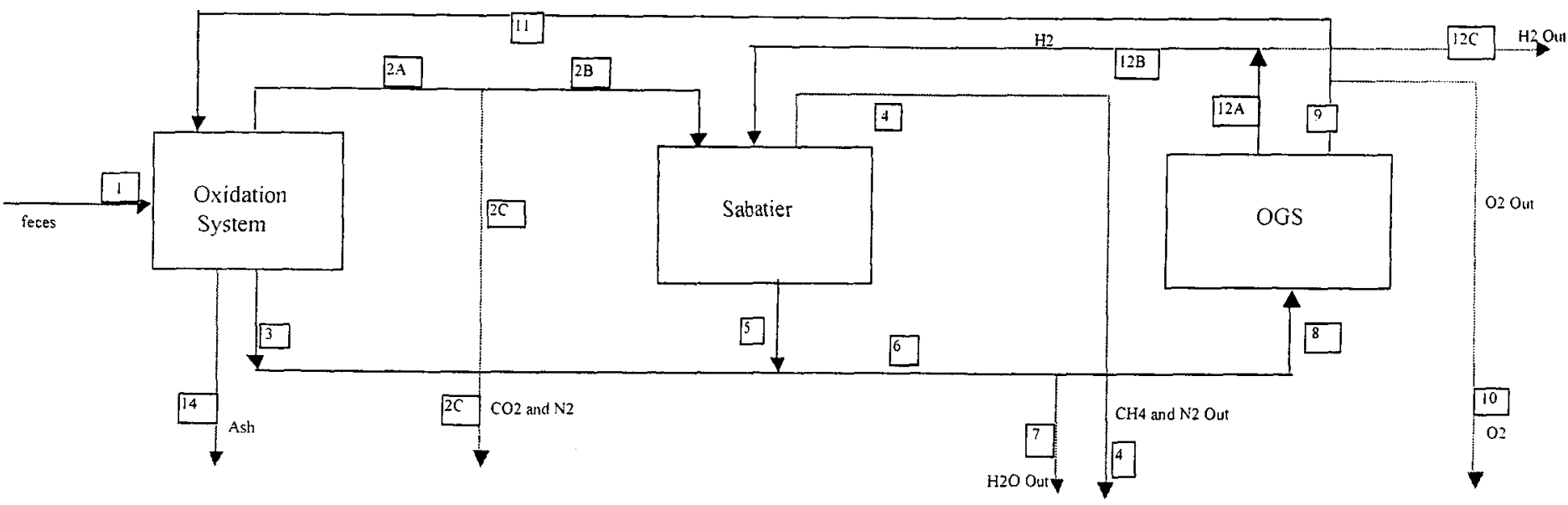

Figure 2, Flow-diagram of the integrated oxidation-Sabatier-OGS system

Table 1, Feed composition. Total for 6 Person Crew. Dry Basis.

\begin{tabular}{|l|l|l|l|l|l|l|l|}
\hline & & & $\mathrm{C}$ & $\mathrm{H}$ & $\mathrm{O}$ & $\mathrm{N}$ & \\
\hline Name & Rate(kg/d) & Formula & $\mathrm{a}$ & $\mathrm{b}$ & $\mathrm{C}$ & $\mathrm{d}$ & Mol.Wt \\
\hline Feces & 0.18 & $\mathrm{C}_{42} \mathrm{H}_{69} \mathrm{O}_{13} \mathrm{~N}_{5}$ & 42 & 69 & 13 & 5 & 851 \\
\hline Toilet paper & 0.138 & $\left(\mathrm{C}_{6} \mathrm{H}_{10} \mathrm{O}_{5}\right) \mathrm{n}$ & 6 & 10 & 5 & 0 & 162 \\
\hline Urine solid & 0.36 & $\mathrm{C}_{2} \mathrm{H}_{6} \mathrm{O}_{36} \mathrm{~N}_{2}$ & 2 & 6 & 3.6 & 2 & 115.6 \\
\hline Wash water solid & 0.06 & $\mathrm{C}_{13} \mathrm{H}_{28} \mathrm{O}_{13} \mathrm{~N}_{2}$ & 13 & 28 & 13 & 2 & 420 \\
\hline Sweat solid & 0.12 & $\mathrm{C}_{13} \mathrm{H}_{28} \mathrm{O}_{13} \mathrm{~N}_{2}$ & 13 & 28 & 13 & 2 & 420 \\
\hline Paper (cellulose) & 0.349 & $\left(\mathrm{C}_{6} \mathrm{H}_{10} \mathrm{O}_{5}\right) \mathrm{n}$ & 6 & 10 & 5 & 0 & 162 \\
\hline Trash (cellulose) & 0.245 & $\left(\mathrm{C}_{6} \mathrm{H}_{10} \mathrm{O}_{5}\right) \mathrm{n}$ & 6 & 10 & 5 & 0 & 162 \\
\hline & & & & & & & \\
\hline
\end{tabular}


Table 2, Input and Output Components (mixed waste stream)

\begin{tabular}{|l|c|l|}
\hline Calculation Basis & & \\
\hline $\begin{array}{l}\text { Water in wet mixed } \\
\text { wastes(\%) }\end{array}$ & 83 & $\%$ \\
\hline Batch size: & 1 & Per day \\
\hline $\begin{array}{l}\text { Mixed Waste dry } \\
\text { weight/person/day }\end{array}$ & 142 & $\mathrm{~g}$ \\
\hline $\begin{array}{l}\text { Mixed waste dry } \\
\text { weight/batch }\end{array}$ & $\mathrm{g}$ \\
\hline Number of crew members & 6 & persons \\
\hline
\end{tabular}

\begin{tabular}{|c|c|c|c|}
\hline \multicolumn{4}{|c|}{$\begin{array}{l}\text { Mixed waste elemental breakdown (dry weights based on } \\
\text { table } 1 \text { above) }\end{array}$} \\
\hline wet wastes & wet formula & dry formula & dry wt. $\%$ \\
\hline$C$ & 1.00 & 1.00 & 35.40 \\
\hline $\mathrm{H}$ & 20.28 & 1.89 & 5.58 \\
\hline 0 & 10.081 & 0.89 & 42.01 \\
\hline $\mathrm{N}$ & 0.17 & 0.17 & 7.02 \\
\hline ash & $* * *$ & $\cdots$ & 10.00 \\
\hline total & & & 100.00 \\
\hline
\end{tabular}

\begin{tabular}{|l|c|c|c|c|}
\hline Component & $\begin{array}{c}\text { Input } \\
\text { g/day }\end{array}$ & $\begin{array}{c}\text { Input } \\
\text { Stream } \\
\text { number in } \\
\text { figure 2 }\end{array}$ & $\begin{array}{c}\text { Output } \\
\text { g/day }\end{array}$ & $\begin{array}{c}\text { Output } \\
\text { Stream } \\
\text { number in } \\
\text { figure 2 }\end{array}$ \\
\hline Wet waste & 8541 & 1 & & \\
\hline $\mathrm{CH}_{4}$ & & & 685 & 4 \\
\hline $\mathrm{H}_{2} \mathrm{O}$ & & & 6275 & 7 \\
\hline $\mathrm{CO}_{2}$ & & & 0 & $2 \mathrm{C}$ \\
\hline $\mathrm{O}_{2}$ & & & 1332 & 10 \\
\hline $\mathrm{H}_{2}$ & & & 0 & $12 \mathrm{C}$ \\
\hline $\mathrm{N}_{2}$ & & & 101 & $2 \mathrm{C}, 4$ \\
\hline Ash & & & 145 & 14 \\
\hline Total & 8541 & & 8541 & \\
\hline
\end{tabular}


Table 3, Input and Output Components (feces only waste stream)

\begin{tabular}{|l|c|l|}
\hline Calculation Basis & & \\
\hline Water content in feces(\%) & 80 & $\%$ \\
\hline Batch size: & 1 & Per day \\
\hline $\begin{array}{l}\text { Feces dry } \\
\text { weight/person/day }\end{array}$ & 39 & $\mathrm{~g}$ \\
\hline feces dry weight/batch & 234 & $\mathrm{~g}$ \\
\hline Number of crew members & 6 & persons \\
\hline
\end{tabular}

\begin{tabular}{|c|c|c|c|}
\hline \multicolumn{4}{|c|}{$\begin{array}{l}\text { Feces elemental breakdown (dry weight formula from } \\
\text { Carden, 1982) }\end{array}$} \\
\hline feces & wet formula & dry formula & dry $w \%$ \\
\hline C & 1.00 & 1.00 & 41.89 \\
\hline $\mathrm{H}$ & 14.69 & 1.96 & 6.84 \\
\hline $\mathrm{O}$ & 6.95 & 0.59 & 32.96 \\
\hline$N$ & 0.17 & 0.17 & 8.31 \\
\hline ash & $\star * * *$ & $-->$ & 10.00 \\
\hline total & & & 100.00 \\
\hline
\end{tabular}

\begin{tabular}{|l|c|c|c|c|}
\hline Component & $\begin{array}{c}\text { Input } \\
\text { gm/day }\end{array}$ & $\begin{array}{c}\text { Input } \\
\text { Stream } \\
\text { number in } \\
\text { figure 2 }\end{array}$ & $\begin{array}{c}\text { Output } \\
\text { gm/day }\end{array}$ & $\begin{array}{c}\text { Output } \\
\text { Stream } \\
\text { number in } \\
\text { figure 2 }\end{array}$ \\
\hline Wet feces & 1170 & 1 & & \\
\hline $\mathrm{CH}_{4}$ & & & 130 & 4 \\
\hline $\mathrm{H}_{2} \mathrm{O}$ & & & 786 & 7 \\
\hline $\mathrm{CO}_{2}$ & & & 0 & $2 \mathrm{C}$ \\
\hline $\mathrm{O}_{2}$ & & & 210 & 10 \\
\hline $\mathrm{H}_{2}$ & & & 0 & $12 \mathrm{C}$ \\
\hline $\mathrm{N}_{2}$ & & & 19 & $2 \mathrm{C}, 4$ \\
\hline Ash & & & 23 & 14 \\
\hline Total & 1170 & & 1170 & \\
\hline
\end{tabular}

\section{Table 4, Assumptions Used in ESM Calculations}

Mars transit ESM Conversion Factors (BVAD. 1999)

\begin{tabular}{|l|l|}
\hline Volume $\left(\mathrm{kg} / \mathrm{m}^{3}\right)$ & 16.1 \\
\hline Power $(\mathrm{kg} / \mathrm{kW})$ & 83.3 \\
\hline
\end{tabular}

Mars Planetary ESM Conversion Factors (BVAD, 1999)

\begin{tabular}{|l|l|}
\hline Volume $\left(\mathrm{kg} / \mathrm{m}^{3}\right)$ & 2.083 \\
\hline Power $(\mathrm{kg} / \mathrm{kW})$ & 86.95 \\
\hline
\end{tabular}

ESM for Sabatier and OGS, crew of six (BVAD, 1999)

\begin{tabular}{|l|c|c|c|}
\hline & mass & volume $\left(\mathrm{m}^{3}\right)$ & power $(\mathrm{kW})$ \\
\hline Sabatier & 182 & 0.21 & 0.2 \\
\hline OGS & 377 & 1.1 & 1.84 \\
\hline
\end{tabular}


Table 5, Partial Breakdown of ESM Values for Oxidation-Sabatier-OGS and Lyophilization - Before Considering Water Recovery Effects

Mars

transit

\begin{tabular}{|l|c|c|}
\hline & $\begin{array}{c}\text { Wet feces } \\
\text { only }\end{array}$ & All wet trash \\
\hline & ESM $(\mathrm{kg})$ & ESM $(\mathrm{kg})$ \\
\hline OGS & 52 & 272 \\
\hline Sabatier & 12 & 62 \\
\hline Oxidation* & 61 & 412 \\
\hline & 125 & 747 \\
\hline
\end{tabular}

Note: Mars Surface ESM values are essentially the same because the power penalties are roughly the same and the volume penalties are negligible.

Table 6: ESM values for the oxidation-Sabatier-OGS system in comparison with combined Autoclaving-Lyophilization With Water Effects Included.

Note: "Venting" refers to the fact that the autoclave-lyophilization system produces gases that must either be vented overboard or treated for habitat internal release. Treatment for internal release (nonventing) increases the ESM somewhat.

Wet Feces Only, Mars Transit

\begin{tabular}{|l|c|c|}
\hline ESM & OGS-SAB-Oxidation, (kg) & $\begin{array}{c}\text { Autoclave- } \\
\text { Lyophilization, } \\
\text { (kg) }\end{array}$ \\
\hline ESM with venting & 125 & 80 (Lee, 2001) \\
\hline Water recovered/600 days & -597 & -544 \\
\hline Total system ESM with venting & -472 & -464 \\
\hline Oxidation system has a lower overall ESM by $8 \mathrm{~kg}$. \\
\hline \multicolumn{2}{|c|}{-472} & -427 \\
\hline Total system ESM for no venting & - & \\
\hline Oxidation system has a lower overall ESM by $45 \mathrm{~kg}$. \\
\hline
\end{tabular}

All Wet Wastes Except Plastic Packaging, Mars Transit

\begin{tabular}{|l|c|c|}
\hline ESM & OGS-SAB-Oxidation, (kg) & $\begin{array}{c}\text { Autoclave- } \\
\text { Lyophilization, } \\
\text { (kg) }\end{array}$ \\
\hline ESM with venting & 747 & 550 (Lee, 2001) \\
\hline Water recovered/600 days & -4591 & -4125 \\
\hline Total system ESM & -3843 & -3575 \\
\hline Oxidation system has a lower overall ESM by $268 \mathrm{~kg}$. \\
\hline \multicolumn{3}{|c|}{-3843} \\
\hline System ESM for no venting & -3295 \\
\hline Oxidation system has a lower overall ESM by $548 \mathrm{~kg}$. \\
\hline
\end{tabular}

